\title{
I NFECTIONS
}

JUNE E. OSBORN, MD

In regard to infections as a determinant of the health status of urban populations, three general points are clear from the vantage points of microbiology and epidemiology. First, moderately pathogenic microorganisms often enhance their virulence in rapid host-to-host passage; crowding serves them well. Second, infectious diseases tend to be more severe in people whose health status is compromised by factors common to urban life, such as poverty, marginal nutritional status, or both. Third, the synergy of both of those factors means that urban concentrations provide the optimal point for introduction and amplification of new and re-emerging infections. Since by training I am much more a microbiologist than an epidemiologist, I approach my subject from the microbe's point of view. This paper focuses on urbanization and what it does to and for pathogenic microorganisms.

The literature concerning emerging and re-emerging infections is growing rapidly. The Centers for Disease Control and Prevention (CDC) have devoted a new journal to the topics. Such renewed interest in a publication devoted to infectious diseases parallels the renewed interest that physicians are experiencing. My own medical career reflects that renewal. It sorts rather neatly into two halves: the first spanned much of the exciting era in which insight into infectious diseases deepened almost to the point of ostensible conquest, not to mention hubris; the second has been dominated by the glowering specter of acquired immunodeficiency syndrome (AIDS) and the re-emergence of bacterial pathogens that had developed resistance to antibiotics, making it all too clear that the seeming victory had been illusory.

The facts of crowded life have pertained throughout the whole era of modern medicine; examples from the early antibiotic era are instructive. Subsequently, the AIDS years offered new lessons about emerging infections. Both experiences suggest to me that urbanization will continue to favor the microbes until we

Dr. Osborn is President, Josiah Macy, Jr., Foundation, 44 East 64th Street, New York, NY 10021 
raise both the minimum economic status and the minimum educational level of our urban citizenry.

\section{EMERGENCE OF THE ANTIBIOTIC ERA}

Crowding and poverty are key variables in both the transmission and the virulence of infectious disease pathogens. In their studies of the virulence of group A streptococcal infections and their nonsuppurative sequelae, acute rheumatic fever and acute glomerular nephritis, Rammelkamp and associates ${ }^{1}$ postulated a major role for $\mathrm{M}$ protein and then observed, in a boot camp military context, that rapid man-to-man passage greatly enhanced the abundance of $M$ protein produced by the streptococci, which in turn correlated with a fully 10 -fold enhancement of rheumatogenic activity following acute infection. Thus, crowding and rapid interhuman passage were strongly implicated as factors that worked in the direction of enhanced pathogenicity.

Until recently, streptococcal infections seemed to undergo a decline in severity even before, and certainly following, the antibiotic era. Scarlet fever, caused by those group A streptococci that could manufacture what used to be called erythrogenic toxin, was a major disease with an appreciable mortality, but it faded almost literally. By the time I became a pediatrician, the scarlatina rash was rarely recognized. In fact, the most frequent way one knew that a streptococcal infection had indeed involved erythrogenic toxin occurred when a parent called in alarm, exclaiming that their child's skin was peeling off in sheets. Often, that was the first retrospective clue of a strep throat, since both the pharyngitis and the rash had been so minor as to be missed. Nonsuppurative sequelae had eased as well. In 1962, when I was at Massachusetts General Hospital, I was caring for a five-year-old child from inner-city Boston who had both severe rheumatic fever and severe acute glomerular nephritis. The case was an extreme rarity for that era, but the attending physician made the point that it had once been far more common to see both sequela in the same patient if the right streptococci were involved and if the patient was impoverished. The lesson I took home was that my patient's socioeconomic disadvantage had, in fact, been sufficiently severe to re-create the human substrate of an earlier era.

Turning to a different, but obvious, example, tuberculosis had been the great plague of European populations during the 19th and early 20th century, so much so that it had been difficult to sort out different virulence factors. Then, as bacteriology matured and World War II again provided conveniently crowded populations for study, the distinction between infection and disease began to be appreciated, as did the precise relationship among cavitation, aerosol droplet size, and necessary degrees of crowding to achieve transmission to a new host. 
By the 1950s, it became possible virtually to prescribe an optimal circumstance for transmission of Mycobacterium tuberculosis. The developed concept of latency led to understanding of tuberculosis transmission, pathogenesis, and disease through insights that we continue to ignore today. In an isolated setting, Mycobacterium tuberculosis would not flourish. In the crush of modern humanity, however, its opportunities are clear and abundant. The topic of multidrug-resistant tuberculosis now commands our attention.

A different and fascinating example of the importance of urban population density on the fate of pathogens is measles, which has no natural host beyond Homo sapiens. Thanks to the brisk and durable immune response to measles when it is introduced into susceptible populations, it has been carefully calculated and generally agreed that measles virus needs a human population of at least half a million to sustain itself during interepidemic intervals. It is on that basis that hope now thrives that measles will go the way of smallpox and, it is hoped, polio, for if comprehensive immunization programs are pursued with vigor, fully resistant populations would offer the measles virus no place to flourish.

Finally, and most unsettlingly, sexually transmitted infections clearly thrive in an urban setting. Microbes that can perpetuate themselves in the context of human sexual intercourse have an obvious winning strategy for survival and, quite probably, for amplification of virulence, all the more so if they produce minimal or no symptoms of infection, as is true of many of the so-called STD (sexually transmitted disease) organisms. Those properties are advantageous to the microbes in direct proportion to the number and variety of sexual partnerships, which in turn seems to relate fairly directly to both crowding and the socially destabilizing aspects of urbanization.

An anecdote from the years immediately preceding the advent of AIDS may illustrate my theme of microbial advantage. In 1975, the director of the National Institute of Allergy and Infectious Diseases was sufficiently alarmed by the rising prevalence of sexually transmitted diseases that he sent out a call for program project proposals and developed a small team of microbiologists to do site visits. Since the call specified the importance of basic epidemiologic and clinical work that occurred in the same setting, the responses came from big urban centers. At that time, I was a virologist specializing in cytomegalovirus (CMV) and herpes viruses and, since $C M V$ and herpes simplex viruses were very prevalent among the concerns of sexually transmitted diseases, I was asked to be one of the microbiologists on the team. Over the five years from 1975 to 1980, we traveled to the cities in the United States where, as we later learned, the human immunodeficiency virus (HIV) was spreading rapaciously, but silently. Although we did not know about HIV and AIDS per se, we did notice and worry about the rapidly 
increasing numbers of sexual partners being reported by people participating in the studies. It seemed evident that microbiologic trouble of some kind lay ahead. For example, Entamoeba histolytica, which had been virtually absent from the United States, was being found with increasing frequency in urban areas in which high levels of anal sexual activity obtained. Hepatitis B, which normally posed a lifetime threat of not more than $1 \%$ to US populations, was found in the classic studies of Szmuness et al., ${ }^{2}$ conducted in the late 1970s, to have an incidence of $12 \%$ per year in highly sexually active populations in New York City.

\section{ACQUIRED IMMUNODEFICIENCY SYNDROME}

It was clear to us that the microbiological stage was set for something. Then, in 1981 , that something surfaced. With a median latency of 7 to 10 years before production of overt disease, HIV had spread exponentially during the 1970 s as we watched but did not see. Epidemiologic studies were not done at first. Although epidemiology had strengthened greatly as a science over the decades preceding the 1980s, it was still viewed as soft and was, therefore, undervalued.

To a dispassionate eye, it seemed evident that blood and sex, and not injection, aerosol, or touch, were the modes of transmission of what we learned to know as HIV. That conclusion could be documented firmly within four years of the first clinically recognized cases. It was the single most important fact we needed to know, since it meant that, once the blood supply was secured, education for prevention could work immediately, even as bench scientists continued their labors to untangle the complicated virologic conundrum. But, the people with HIV disease who had, de facto, served as sentinels heralding the arrival of a new epidemic human pathogen were so marginalized and devalued that their stigmatized status dulled the senses, not to mention the sense, of humanity. Homophobia reigned, and public denial deepened when, within only a year or so of the first reported AIDS cases, the link to injecting drug use was established. So close did that connection prove to be that, when serologic tests became available to ascertain HIV seropositivity, the computer display of AIDS cases along the East Coast looked like a map of Interstate Highway 95, with peaks correlating rather exactly with the known geography of combined illicit drug trafficking and restricted needle access.

In only 16 years, since the first recognized and reported cases of HIV-induced disease in the United States, more young people have been diagnosed with AIDS than the total who have died in all the armed conflicts in which America has been engaged since the Civil War. More than a quarter million Americans are dead, an almost equal number are living with AIDS, and it is estimated that nearly a million more are infected. 
I cannot join wholeheartedly in the relief that people seem to feel at the fact that only 50,000 new cases of AIDS were diagnosed last year. The greatest number of paralytic polio cases in the worst epidemic summers of the 1950 s never reached that number. Nor dare I take comfort in the transient bloom of protease inhibitors, since I know as a virologist that resistance is on the way and that, for most of the people caught in the path of HIV, combination therapies are as personally relevant as a moon landing.

What lessons can we derive from the AIDS epidemic? In terms of urban health, I think the specific case speaks for itself. All the elements were there to recognize and analyze in advance, but they did not help then and still do not seem to help now: witness the continued federal paralysis with respect to drug treatment, needle exchange, and other harm-reduction steps. On a more positive note, however, as the 1990s began, the most important lessons gained from the AIDS pandemic experience did get a hearing thanks to the diligent and persistent efforts of Joshua Lederberg, Steven Morse, and Robert Shope, among others. The Institute of Medicine empaneled a group to investigate both emerging and reemerging infections; their deliberations brought into sharp focus what had, until then, only been looming shadows. It was made clear that the combined forces of international travel, urbanization, social destabilization, and associated changes in sexual mores offer distinct ecologic opportunities for several related retroviruses that had been relatively quiescent in global terms.

Pandora's imps were out of the box. Within 20 years of initiating pandemic spread, HIV-related infections had circled the globe. The story continues. The rapidity with which HIV-1 subtypes are evolving is truly alarming. Without question, there are more microbiological surprises where those came from, and the lessons must now be learned quickly.

\section{LEARNING FROM PRIOR FAILURES}

As urbanity becomes the dominant mode of human existence and isolated ecologic enclaves are deeply disturbed or destroyed, new horizons open not only for pathogens that travel by aerosol or touch, but also for those that ride the wings of social destabilization and associated events, including drug use and multiple sexual partnerships. Our recent inadequate response to AIDS, which may prove to have been a prototypic challenge, should teach us to be more attentive in the future. I suggest four considerations that should obtain as we attempt to do this.

First, the industrialized world has turned ever more reflexively to technology as the dominant vehicle to solve human problems. So striking has that mind-set been that low-technology solutions-behavior change, education for prevention, 
needle exchange, and so forth-continue to be undervalued or, indeed, rebuffed, whereas cries for mandatory testing, high-tech RNA screening of blood, and so forth dominate the mood. I have no quarrel with technological input to an overall response for prevention and control, but its dominance is dangerous and has led repeatedly to abandonment of so-called softer science insights out of convenience and in the face of both data and common sense.

Second, marginalization, stigma, and discrimination have been major engines for the spread of HIV and AIDS. In my view, the potential to drive that and any other similar epidemic underground through blame-the-victim approaches is always present and most frightening. Yet, hostile social forces that raise fear of disclosure in the hearts of sick people have yet to be recognized as the killers of humanity that they are.

Third, we need to discern, as has been beautifully articulated by my colleague, Jonathan Mann, that there is an inextricable link between health and human rights, and that this linkage must be nurtured and should factor heavily into our thinking and planning. The strict linearity of the association between health and economic well-being is quite startling, and we are increasingly concentrating the lowest portions of that curve in conditions of urban crowding and despair in ways that threaten the health of the entire community. The point of another colleague, David Lewis, might be observed when arguing for increased treatment of people who are addicted: one should think of drug treatment for the addicted user as prevention for the community as a whole.

Fourth, the global village has, in fact, become a global city. Not only are the megametropolises of recent decades burgeoning worldwide, but also they are often doing so without benefit even of present knowledge about sustainable urban government and infrastructure. This shortcoming was driven home to me during a trip to Zaire in 1989. As we rode over a nearly impassable urban street on the way to visit a hospital, I saw a little boy, about 8 years old, sleeping peacefully at the crest of a hill of garbage 10 feet high. That image is burned in my mind forever.

Finally, from an infectious disease point of view, it is important to note that all the rules that govern microbial virulence and transmission in the city can pertain equally well to the countryside. It is easy to illustrate that point again with the AIDS epidemic, for the fastest-growing part of the epidemic in the United States has been observed for many years in smaller and smaller communities and in the rural South, where people foolishly dismiss things such as AIDS as being urban.

I close in reprise that my infectious disease career fell roughly into two conceptual halves: the first was dominated by the glee of initial success at treat- 
ment and vaccine development, and a sense of conquest exemplified by smallpox eradication; the second was dominated by a glowering, growing shadow of realism that imported to those who saw it and paid heed that, in the context of our modern crowded world, we have not seen the end of microbes. Indeed, we have seen only the beginning. The health of urban humanity depends greatly on whether we learned our lessons and got them right. I am very worried about our apparent failure to learn.

\section{REFERENCES}

1. Rammelkamp CH, Wannamaker LW, Denny FW. The epidemiology and prevention of rheumatic fever. Bull NY Acad Med. 1952;28:321-324.

2. Szmuness $W$, Stevens $C E$, Harley EJ et al. Hepatitis $B$ vaccine: demonstration of efficacy in a controlled clinical trial in a high risk population in the United States. $N$ Engl J Med. 1980;303:833-841. 